\title{
Erkek partnerin cinsel hayatında genel memnuniyet ile en fazla ilișkili IIEF parametreleri
}

\section{The most associated IIEF Parameters with the overall satisfaction in sexual life of the male partner}

\author{
Mehmet Caniklioğlue, Fatih Fırat®
}

\section{öz}

AMAÇ: Uluslararası erektil ișlev formu (IIEF) her ne kadar erektil işlevlerin (EI) değerlendirilmesi için kullanılmış olsa da bize sağlıklı bir cinsel hayatın ipucu olabilecek başka parametreler de sunmakta mıdır? Sorusundan hareketle elimizdeki veriler ışığında genel memnuniyet (GM) skoruna en fazla etki eden parametreleri araştırmayı amaçladık.

GEREC ve YÖNTEMLER: 157 hastanın IIEF verileri retrospektif olarak analiz edildi. Eİ, ilişki memnuniyeti (İM), orgazmik işlev (Oİ) ve cinsel istek (Cİ) ayrı ayrı skorlanıp GM açısından tüm verilere kuantil regresyon analizi yapıldı.

BULGULAR: Erektil işlev (Eİ) ve CI'nin GM ile ilişkisi yer yer devamlılığını kaybetmekteydi. Oİ ve CM skorları GM ile en tutarlı pozitif korelasyonu gösteren parametrelerdi.

SONUC̣: Genel memnuniyet (GM) üzerine Eİnin öneminin fazla olduğu düşünülse de bu çalışmanın sonuçlarına göre tüm persentiller göz önüne alındığında erkek partner, cinsel hayatının tamamında memnuniyetini değerlendirirken kendi cinsel performansına ve kendi orgazmının kalitesine odaklanmaktadır.

Anahtar Kelimeler: IIEF, cinsel memnuniyet, regresyon, korelasyon, genel memnuniyet skoru, orgazm

\section{Gíriș}

Erektil disfonksiyon (ED) tatminkâr bir seksüel performansı olumsuz etkileyecek düzeyde ereksiyon ve ereksiyonu sürdürme yetersizliğidir. ${ }^{[1]}$ Literatürde insidansı ile alakalı \%19-52 arasında değişen rakamlar verilmiştir. ${ }^{[2-5]}$ Etyolojide vasküler, nörojen ve hormonal parametreler

${ }^{7}$ Yozgat Bozok Üniversitesi Tıp Fakültesi, Üroloji Anabilim Dalı, Yozgat, Türkiye ${ }^{2}$ Tokat Devlet Hastanesi, Üroloji Bölümü, Tokat

Yazışma Adresi/ Correspondence:

Dr. Öğr. Üyesi Mehmet Caniklioğlu

Yozgat Bozok Üniversitesi Tıp Fakültesi, Üroloji Anabilim Dalı 66100 Yozgat, Türkiye Tel: $\quad$ +905362915732

E-mail: dr.mehmetcaniklioglu@gmail.com

Geliş/ Received: $\quad 05.08 .2020$

Kabul/ Accepted: $\quad 22.09 .2020$

\section{ABSTRACT}

OBJECTIVE: Although the international form of erectile function (IIEF) has been used to evaluate erectile function (EI), does it provide us with other parameters that may be a clue to a healthy sex life. Based on the question, we aimed to investigate the parameters that affect the overall satisfaction (GM) score in the light of the available data.

MATERIAL and METHODS: The IIEF data of 157 patients were analyzed retrospectively. Quantile regression analysis was performed in terms of OS, separately for EF, sexual satisfaction (SS), orgasmic function (OF) and sexual desire (SD).

RESULTS: EF and SD's relationship with GM lost its continuity in percentilles. OF and SS scores were the most consistent positive correlations with OS.

CONCLUSION: Although the importance of EF on OS is considered to be high, considering all the percentiles according to the results of this study, the male partner focuses on his own sexual performance and the quality of his orgasm while evaluating his satisfaction in the whole of his sexual life.

Keywords: IIEF, sexual satisfaction, regression, correlation, overall satisfaction score, orgasm

gibi organik sebeplerin yanı sıra önemli oranda da psikomental faktörler etkilidir. ${ }^{[6,7]}$

Uluslararası erektil işlev skoru (IIEF) yıllardır erektil fonksiyonların değerlendirilmesinde en yaygın olarak kullanılan, etkin ve güvenilir bir araçtır. ${ }^{[8,9]}$ Genel anlamda IIEF, ED'nin tanı ve tedavi takibinde kullanılan gerek klinik gerekse de akademik bir araçtır. Uluslararası erektil işlev skoru'nun cinsel sağlığın non-erektil faktörleri olan psikomental komponentlere odaklandığını söylemek güçtür. Bununla birlikte, psikometrik bir skorlama olması yönüyle genel memnuniyet (GM) ve ilişki memnuniyeti (IM) gibi diğer parametreleri de ölçebilecek şekilde tasarlanmıştır. ${ }^{[10]}$

İM bireylerin ilişkiden ne düzeyde memnun kaldığını gösteren daha ziyade erkek faktörüne yönelik bir sorgulama 
iken GM skoru aslında kısmen partner birlikteliğinden doğan memnuniyete de işaret eden bir skordur. Rosen ve ark.'nın 14. soruyu hazırlarken partnere yönelik tasarlamış olmaları buna bir işarettir. ${ }^{[9]}$

Ereksiyon fizyolojisinde çok karmaşık faktörlerin bulunduğu bilinmektedir. ${ }^{[11]}$ IIEF'nin ölçebildiği cinsel sağlık ile alakalı parametrelerin hangisinin GM'yi daha çok etkilediği ile alakalı ya da bu parametrelerin birbiri ile ilişkilerini konu alan bir çalışma bulunmamaktadır. Biz bu çalışmada IIEF'nin ölçtüğü parametrelerin birbiri arasındaki ilişkiyi değerlendirmeyi ve GM üzerine en fazla olumlu etki gösteren parametreyi ortaya çıkarmayı amaçladık.

\section{GEREÇ VE YÖNTEMLER}

Çalışmada Ekim 2017 - Mart 2020 tarihleri arasında kliniğimize erkek faktörlü infertilite araştırması için başvurmuş 748 hastanın dosyası incelendi. Kırk yaşından büyük hastalar, endokrin ve metabolik bozukluğu olanlar (diyabetes mellitus, hipogonadizm, hipo/hipertiroidi, hiperprolaktinemi, vitamin D eksikliği), kronik hastalığı olanlar (hipertansiyon, kardiovasküler hastalık, obstrüktif uyku apnesi sendromu, vb.), kronik ilaç kullanım öyküsü olanlar, depresyon tanısı olan ve tedavi görenler çalışmadan dışland ${ }_{.}{ }^{[6,12]}$ Hastalardan rütin olarak istenen IIEF formlar1 retrospektif olarak analiz edildi. Formları ve laboratuvar sonuçları eksiksiz olan 157 hastanın verileri ile çalışmanın analizleri yapıldı.

Hastalardan IIEF formlarını kendi başlarına, sakin bir ortamda doldurmaları istendi. Erektil işlev (Eİ) fonksiyonları için $1-5$ ve 15 . soruların toplamları değerlendirmeye alındı. Buna göre $0-10$ arası puan alan hastalar ciddi ED, 11-16 puan arası alanlar orta dereceli ED, 17-21 puan arası alanlar hafif-orta dereceli ED, 22-25 puan arası alanlar hafif dereceli ED ve 26-30 puan alanlar ED yok olarak yorumland.

Formlardan elde edilen verilere göre diğer cinsel sağlık parametreleri de skorlanıp kayıt altına alındı. İM için 6-8. soruların, orgazmik işlev (Oİ) için 9-10. soruların, cinsel istek (CI) için 11-12. soruların ve GM için 13-14. soruların toplamı değerlendirmeye alındı.

Grupların dağılımları için Kolmogorov-Smirnov ve Shapiro-Wilk testleri uygulandı. Tanımlayıcı istatistikler ile hastaların demografik verilerinin gösterimleri yapıldı. Y değeri GM skoru olarak alındı ve nonparametrik dağılımlar için kuantil regresyon analizi uygulanarak faktörlerin $5,25,50,75$ ve 95 persentillerdeki ilişkilerine bakıldı. p değerinin 0,05'ten küçük olması istatistiksel olarak anlamlı kabul edildi.

\section{BULGULAR}

Hastalara ait demografik veriler, IIEF skorları ve laboratuvar analizleri tablo 1'de özetlenmiştir. Grubun yaş ortalaması $29,97 \pm 4,80$, beden kitle indeksi (BKİ) ise $26,54 \pm 4,11$ olarak raporlandı. İlişki sıklığı ortalaması haftada $1,93 \pm 0,28$ idi. IIEF skorlarına bakıldığında EI ortalaması 26,32 $\pm 4,36$ idi. 108 hastanın $(\% 68,8)$ ED'si yoktu. Kalan hastalardan 27 'sinin $(\% 17,2)$ hafif dereceli, 16 'sinın $(\% 10,2)$ hafif-orta dereceli, 5 'inin orta dereceli $(\% 3,2)$ ve 1 'inin $(\% 0,6)$ ciddi dereceli ED'si vardı. Diğer IIEF faktörlerine bakıldığında İM ortalaması 12,05 $\pm 2,23$; Oİ ortalaması $9,16 \pm 1,42$; Cİ ortalaması 7,63 $\pm 1,48$; GM skoru $8,58 \pm 1,48$ idi.

Hormonal analizlerde de folliküler stimülan hormon (FSH)

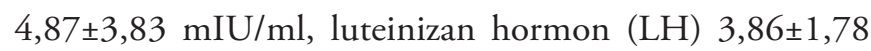
$\mathrm{IU} / \mathrm{ml}$ ve total testosteron (TT) $448,02 \pm 172,21 \mathrm{ng} / \mathrm{dL}$ şeklinde raporlandı. Grubun genelinde IIEF parametre skorları nonparametrik bir dağılım gösterdiği için çoklu regresyon şartları sağlanamadı. Bu nedenle tüm grupta GM skoru hedef değer olarak alınarak IIEF parametreleri açısından kuantil regresyon analizi yapıldı (Tablo-2). Buna göre Eİ 5, 25, 75 ve 95. persentillerde anlamlı düzeyde GM skoru ilişkiliydi $(\mathrm{p}<0,05)$. Oİ skoru 95. persentil hariç tutulduğunda tüm persentillerde GM skoru ile istatistiksel olarak anlamlı düzeyde ilişkileri vardı $(\mathrm{p}<0,05)$. CÍ skoru ise sadece 5,75 ve 95 . persentillerde anlamlı ilişki gösteriyordu. İM skoru ise tüm persentillerde korelasyon gösteriyordu. Yapılan analizlerde anlamlı ilişkiler pozitif korelasyon göstermekteydi ve negatif korelasyon hiçbir parametrede görülmemekteydi.

Tablo 1. Hastalara ait demografik veriler, IIEF skorları ve laboratuvar analizlerinin özeti

\begin{tabular}{lc}
\hline Parametre & Ortalama \pm SS \\
\hline Yaş (yıl) & $29,97 \pm 4,80$ \\
BKi & $26,54 \pm 4,11$ \\
illişki sıklığı (n/hafta) & $1,93 \pm 0,28$ \\
Ei skoru & $26,32 \pm 4,36$ \\
IMM skoru & $12,05 \pm 2,23$ \\
Oi skoru & $9,16 \pm 1,42$ \\
Ci skoru & $7,63 \pm 1,48$ \\
GM skoru & $8,58 \pm 1,48$ \\
FSH (mIU/ml) & $4,87 \pm 3,83$ \\
LH (IU/ml) & $3,86 \pm 1,78$ \\
Total Testosteron (ng/dL) & $448,02 \pm 172,21$ \\
\hline
\end{tabular}

IIEF, international index of erectile function; BKi, beden kitle indeksi; Ei, erektil işlev; IM, ilişki memnuniyeti; Oi, orgazmik işlev; Ci, cinsel istek; GM, genel memnuniyet; $\mathrm{FSH}$, folliküler stimulan hormon; LH, Luteinizan hormon; SS, standart sapma. 
Tablo 2. IIEF verilerine ait kuantil regresyon analizi tablosu

\begin{tabular}{lcccccccccc}
\hline Parametre & $Q=0.05$ & $P$ & $Q=0.25$ & $P$ & $Q=0.50$ & $P$ & $Q=0.75$ & $P$ & $Q=0.95$ & $P$ \\
\hline Ei & 0,167 & $<0,001$ & 0,077 & 0,03 & 0,048 & 0,08 & 0,061 & 0,02 & $<0,001$ & 0,02 \\
iM & 0,22 & 0,004 & 0,38 & $<0,001$ & 0,28 & $<0,001$ & 0,15 & 0,006 & $<0,001$ & $<0,001$ \\
oi & 0,33 & 0,001 & 0,30 & 0,002 & 0,28 & $<0,001$ & 0,15 & 0,006 & $<0,001$ & 0,24 \\
Ci & 0,27 & 0,006 & 0,15 & 0,12 & 0,14 & 0,06 & 0,14 & 0,04 & $<0,001$ & 0,02 \\
\hline
\end{tabular}

Kuantil regresyon tablosunda seçilmiş GM skoru persentilleri boyunca diğer parametrelerin GM skoru ile korelasyon ilişkileri gösterilmiştir. Beşinci persentil en düşük GM skoru değerlerinin temsil ederken 95. persentil en yüksek GM skoru değerlerini temsil etmektedir. Tüm parametrelerin pozitif korelasyon içerisinde olduğu görülmektedir. Ei, Erektil işlev; iM, ilişki memnuniyeti; Oi, Orgazmik işlev; Ci, Cinsel istek. $*_{p}<0,05$

\section{TARTIȘMA}

Cinsellik oldukça karmaşık etmenlerin etki ettiği bir kavramdır Sadece hormonlar, feromonlar, genler ve cinsel uyaranlar ile alakalı değildir. ${ }^{[13-15]}$ Psikososyal etmenler ve çevresel değişimler de cinsel davranışlarımız üzerine oldukça etkilidir. ${ }^{[11,16,17]} \mathrm{Bu}$ bağlamda cinselliğin biyolojik, psikolojik ve toplumsal seviyede değerlendirilmesi gerektiğini vurgulamak gerekir. ${ }^{[18]}$ Biyolojik seviyede cinsellik esas olarak üreme ile neslin devamını hedefleyen bir kavramdır ve süreç işletilebildiği müddetçe cinsel yaşam başarılı kabul edilir. Psikolojik seviyede ise sevme ve sevilme ihtiyacının karşılanmasının yanı sıra kişisel hazlarla mizacın yükselmesi esas hedeftir. Bu doyumlar sağlandığında psikolojik anlamda tatminkâr bir cinsel ilişkiden söz edilebilir. Toplumsal seviyede ise cinsellik örfler, gelenekler, yasalar, cinsiyetçi roller, eş seçimleri gibi faktörler tarafından kuşatılmıştır. Bireylerin, toplumun normlarına uygun ve toplumu rahatsız etmeksizin cinsel yaşamını sürdürmesi ile başarılı bir cinsel hayatın ortaya çıkacağı düşünülür. Cinsellik açısından biyolojik, psikojenik ve toplumsal tanımlara göre kazanılan başarılar, elbette bireyin kendisi ve toplumla barışıklığını artırmakla birlikte cinsel memnuniyeti artıracaktır. Zira tersi bir durumda cinsel açıdan yaşanan olumsuzluklar sevilmeme korkusu, doyum yetersizlikleri, izolasyon, gerginlik, değersizlik gibi psikojenik dışavurumlarla neticelenebilmektedir. ${ }^{[19]}$ Rehman ve ark. çiftlerin birbirine karşı cinsellik açısından açık olması ve paylaşımda bulunmasının da cinsel memnuniyette etkili olduğunu bildirmiştir. ${ }^{[20]}$ Bunlara ek olarak bireylerin cinselliğe verdikleri önem de kendilerine özgüdür ve elbette ki cinsel memnuniyet üzerine bunun da etkisi vardır. ${ }^{[18]}$

Tüm bu etmenlere bakıldığında bu çalışmada kullandığımız IIEF'nin İM ve GM değerlendirmesinde ne derece başarılı olduğu düşünülebilir. Burnett IIEF'nin diğer cinsel parametrelerden ziyade ED tanı ve tedavi takibi için tasarlandığını belirtmektedir. ${ }^{[10]}$ Ancak IIEF'nin psikometrik bir skor olması yönüyle diğer parametreleri de değerlendirebildiğini vurgulamaktadır. Konu cinsel memnuniyete geldiğinde aslında dünyada kullanılan başka skorlama sistemleri bulunmaktadır. ${ }^{[21]}$ Bunlar içerisinden Cinsel Fonksiyonda Değişiklikler Anketi (CSFQ), Derogatis Cinsel Fonksiyon Kişisel Görüşme Formu (DISF) ve Golombok Rust Cinsel Doyum Envanteri (GRISS) erkeklere de uygulanabilir oluşu ile önem arzetmektedir. Ancak yine de IIEF-5'in GM üzerine yaptığı değerlendirmeler eşler düzeyinde değerlendirildiğinde bile hem erkekte hem de eşinde tutarlı sonuçlar vermektedir. ${ }^{[8]}$ Yıllarca hem akademik hem de klinik alanda tutarlılığı gösterilmiş olan IIEF’nin güvenilirliği gösterilmiştir. ${ }^{[10]}$

Bildiğimiz kadarıyla bu çalışma IIEF-5'in ölçtüğü cinsel parametrelerin GM skoru üzerine olan etki düzeyleriyle ve erkeğin cinsel ilişkiye bakışı ile alakalı bilgi vermesi açısından ilk çalışmadır. Rosen ve ark. IIEF'yi ilk kez tasarladıklarında tüm bu parametreler arasında bir korelasyon olup olmadığına bakmışlardır. ${ }^{\left[{ }^{[]}\right.}$Bu çalışmada Eİ ile en yüksek korelasyon gösteren parametreyi İM olarak saptamışlardır. Sözkonusu çalışmadaki veriler incelendiğinde GM ile en yüksek pozitif korelasyon gösteren parametrenin de 0,6 korelasyon katsayısı (orta dereceli ilişki) ile Eİ olduğunu göstermişlerdir. Bizim çalışmamızda ise kuantil regresyon analizi sonuçlarımıza göre, Eİ her ne kadar ilişki memnuniyetinde olmazsa olmaz bir faktör gibi görünse de yer yer anlamlılığının olmadığını gözlemledik. Cİ ise hastaların önemli bir kısmında memnuniyet üzerine bir etki göstermemektedir. İM tüm persentiller boyunca cinsel memnuniyet üzerine anlamlı pozitif bir korelasyon göstermektedir. Orgazm da aynı şekilde 95. persentil dışında tüm çeyreklerde de anlamlı pozitif korelasyon göstermektedir. $\mathrm{Bu}$ bilgiler 1şığında GM üzerine dominant etki gösteren faktörün İM olduğu düşünülebilir. Oİ'nin de neredeyse İM ile paralel seyrediyor olmasından hareketle erkek partnerin kendi performansını ve ilişkiden aldığı hazzı GM kriterleri arasında ön plana aldığı düşünülebilir.

Tablo 2'yi persentiller açısından değerlendirdiğimizde ise 5. persentildeki hastalarda tüm IIEF parametrelerinin önem kazandığını görmekteyiz. Tüm cinsel parametreleri düşük olması genel memnuniyetin azalmasına neden olabilir. 75. persentile kadar Cİ ve Eİ skorlarının yer yer 
anlamlılığını yitirmesi, çalışmanın tek bölgede yapılmış olması da göz önüne alındığında, bu çalışmada olduğu gibi geleneksel toplumlarda cinsel farkındalığın azaldığı, cinsel ilişkinin sadece yerine getirilmesi gereken bir görev gibi algılandığı ve cinsel ilişkide bireyselliğin arttığı düşüncesini destekleyebilir. 75. persentilde ise tüm parametreler yeniden GM açısından önem kazanmakta ve Cİ yeniden devreye girmektedir. 95. persentilde bulunan hastaların ise GM skorlarının Oİ hariç tüm parametreler ilişkisi oldugu görülmektedir. Bu sonuçlardan hareketle GM skorları yükselen persentillerdeki hastalarda cinsel sağlık açısından farkındalık artıyor olabilir. Elbette ki tüm bu yorumlar eldeki verilerin IIEF verileri ile sınırlı olması ve IIEF'nin sübjektifliği sorunu çerçevesinde kısıtlı kalmaktadır.

IIEF formunun sübjektifliği, retrospektif tasarım, bölgesellik bu çalışmanın limitasyonlarıdır. Partner değerlendirmesi yapılmamış oluşu ve hastalara IIEF dışında bir sorgulama (DISF, GRISS, CSFQ) yapılmamış olması da yorum kapasitemizi düşüren limitasyonlar olarak kabul edilebilir.

Sonuç olarak, erkek partnerin cinsel ilişkisini değerlendirirken kendi cinsel performansına ve orgazmının kalitesine odaklandığı söylenebilir. Diğer sorgulama formları ile yapılacak karşılaştırmalı ve daha geniş örneklem içeren çalışmalara ihtiyaç vardır.

\section{Hakem Değerlendirmesi}

Dış bağımsız.

Çıkar Çatışması

Yazarlar çıkar ilişkisi olmadığını beyan etmişlerdir.

\section{Finansal Destek}

Herhangi bir mali destek alınmamıştır.

\section{Peer-review}

Externally peer-reviewed.

Conflict of Interest

No conflict of interest was declared by the authors.

Financial Disclosure

No financial support has been received.

\section{KAYNAKLAR}

1. NIH Consensus Conference. Impotence. NIH Consensus Development Panel on Impotence. JAMA 1993;270:83-90. [CrossRef]

2. Feldman HA, Goldstein I, Hatzichristou DG, Krane RJ, McKinlay JB. Impotence and its medical and psychosocial correlates: Results of the Massachusetts Male Aging Study. J Urol 1994;151:54-61. [CrossRef]

3. Braun M, Wassmer G, Klotz T, Reifenrath B, Mathers M, Engelmann U. Epidemiology of erectile dysfunction: Results of the "Cologne Male Survey. " Int J Impot Res 2000;12:305-11. [CrossRef]

4. Johannes CB, Araujo AB, Feldman HA, Derby CA, Kleinman KP, McKinlay JB. Incidence of erectile dysfunction in men 40 to 69 years old: longitudinal results from the Massachusetts male aging study. J Urol 2000;163:460-3. [CrossRef]
5. Schouten BWV, Bosch JLHR, Bernsen RMD, Blanker MH, Thomas S, Bohnen AM. Incidence rates of erectile dysfunction in the Dutch general population. Effects of definition, clinical relevance and duration of follow-up in the Krimpen Study. Int J Impot Res 2005;17:58-62. [CrossRef]

6. Salonia (Chair) A, Bettocchi C, Carvalho J, Corona G, Jones H, Kadioglu A, et al. European Association of Urology Guidelines on Sexual and Reproductive Health 2020. https://uroweb.org/ guideline/sexual-and-reproductive-health/

7. Corona G, Petrone L, Mannucci E, Mansani R, Balercia G, Krausz C, et al. Difficulties in achieving vs maintaining erection: Organic, psychogenic and relational determinants. Int J Impot Res 2005;17:252-8. [CrossRef]

8. Weiss P, Brody S. International index of erectile function (IIEF) scores generated by men or female partners correlate equally well with own satisfaction (Sexual, partnership, life, and mental health). J Sex Med 2011;8:1404-10. [CrossRef]

9. Rosen RC, Riley A, Wagner G, Osterloh IH, Kirkpatrick J, Mishra A. The international index of erectile function (IIEF): A multidimensional scale for assessment of erectile dysfunction. Urology 1997;49:822-30. [CrossRef]

10. Burnett AL. Commentary RE. The International Index of Erectile Function (IIEF): A Multidimensional Scale for Assessment of Erectile Dysfunction. Urology 2020. [CrossRef]

11. Nimbi FM, Tripodi F, Rossi R, Simonelli C. Expanding the Analysis of Psychosocial Factors of Sexual Desire in Men. J Sex Med 2018;15:230-44. [CrossRef]

12. Capogrosso P, Ventimiglia E, Boeri L, Cazzaniga W, Chierigo F, Pederzoli F, et al. Age at First Presentation for Erectile Dysfunction: Analysis of Changes over a 12-yr Period. Eur Urol Focus 2019;5:899-905. [CrossRef]

13. Lanfranchi A. A Scientific Basis for Humanae Vitae and Natural Law: The Role of Human Pheromones on Human Sexual Behavior Preferences by Oral Contraceptives and the Abortifacient Effects of Oral Contraceptives. Linacre Q 2018;85:148-54. [CrossRef]

14. Sorokowska A, Pietrowski D, Schäfer L, Kromer J, Schmidt AH, Sauter J, et al. Human Leukocyte Antigen similarity decreases partners' and strangers' body odor attractiveness for women not using hormonal contraception. Horm Behav 2018;106:144-9. [CrossRef]

15. Petrulis A. Chemosignals and hormones in the neural control of mammalian sexual behavior. Front Neuroendocrinol 2013;34:25567. [CrossRef]

16. Kontula O, Vaisala L. [How does summer affect sexual desire?]. Duodecim 2013;129:1375-8. https://pubmed.ncbi.nlm.nih. gov/23901739/

17. Corona G, Rastrelli G, Morgentaler A, Sforza A, Mannucci E, Maggi M. Meta-analysis of Results of Testosterone Therapy on Sexual Function Based on International Index of Erectile Function Scores. Eur Urol 2017;72:1000-11. [CrossRef]

18. Schuiling KD, Likis FE. Women's Gynecologic Health, 2nd ed. US: Jones \& Bartlett Learning; 2011.

19. Dokur M, Profeta Y. Aile ve Çift Terapisi. İstanbul: Morpa; 2006.

20. Rehman US, Rellini AH, Fallis E. The importance of sexual selfdisclosure to sexual satisfaction and functioning in committed relationships. J Sex Med 2011;8:3108-15. [CrossRef]

21. Meston CM, Derogatis LR. Validated instruments for assessing female sexual function. J Sex Marital Ther 2002;28:155-64. [CrossRef] 